\title{
Fort McMurray evacuates patients in "surreal" flight
}

$\mathrm{W}$ ith flames from an out-ofcontrol wildfire bearing down on the only hospital in Fort McMurray, Alberta, Dr. Paul Geoffrion had no time to sedate the patient with a dislocated shoulder.

It was 5:15 pm on Tuesday, May 3. Geoffrion and two other emergency department (ED) doctors at Northern Lights Regional Health Centre were working frantically with nurse manager Pamela Lund and her staff to clear emergency. Mandatory evacuations, which would eventually affect close to 90000 people, were taking place across the northern city - but no one had given the order to the ED staff.

Only six hours earlier, when Geoffrion began his shift at $11 \mathrm{am}$, it was a beautiful, if unseasonably warm day. He didn't know that the fire had already doubled in size in less than 24 hours, to cover 2600 hectares. It was shortly after $2 \mathrm{pm}$ when Geoffrion got his first indication of the huge task ahead. Julie Mellon, an ED nurse working at a nearby satellite clinic, phoned Geoffrion to say her clinic was being evacuated. She asked about the hospital's plans.

A lifelong resident of Fort McMurray, Mellon was overwhelmed as she sat in her car, watching her city burn. To her right, an embankment of trees was on fire. Billowing smoke made it difficult to breath. There were so many cars choking the streets that she couldn't head south to leave the city on the only highway.

"I was terrified. I was having a little bit of a panic attack," says Mellon

Geoffrion told her to come to Northern Lights. He thought it was the safest place to be. And she could help them.

At the hospital, Mellon walked into a scene of controlled chaos, which wasn't entirely unusual. On a normal day, doctors see more than 200 patients in the $\mathrm{ED}$ - one of the province's busiest.

Next door to the hosptial, Dr. Dave Murray, who had worked the night

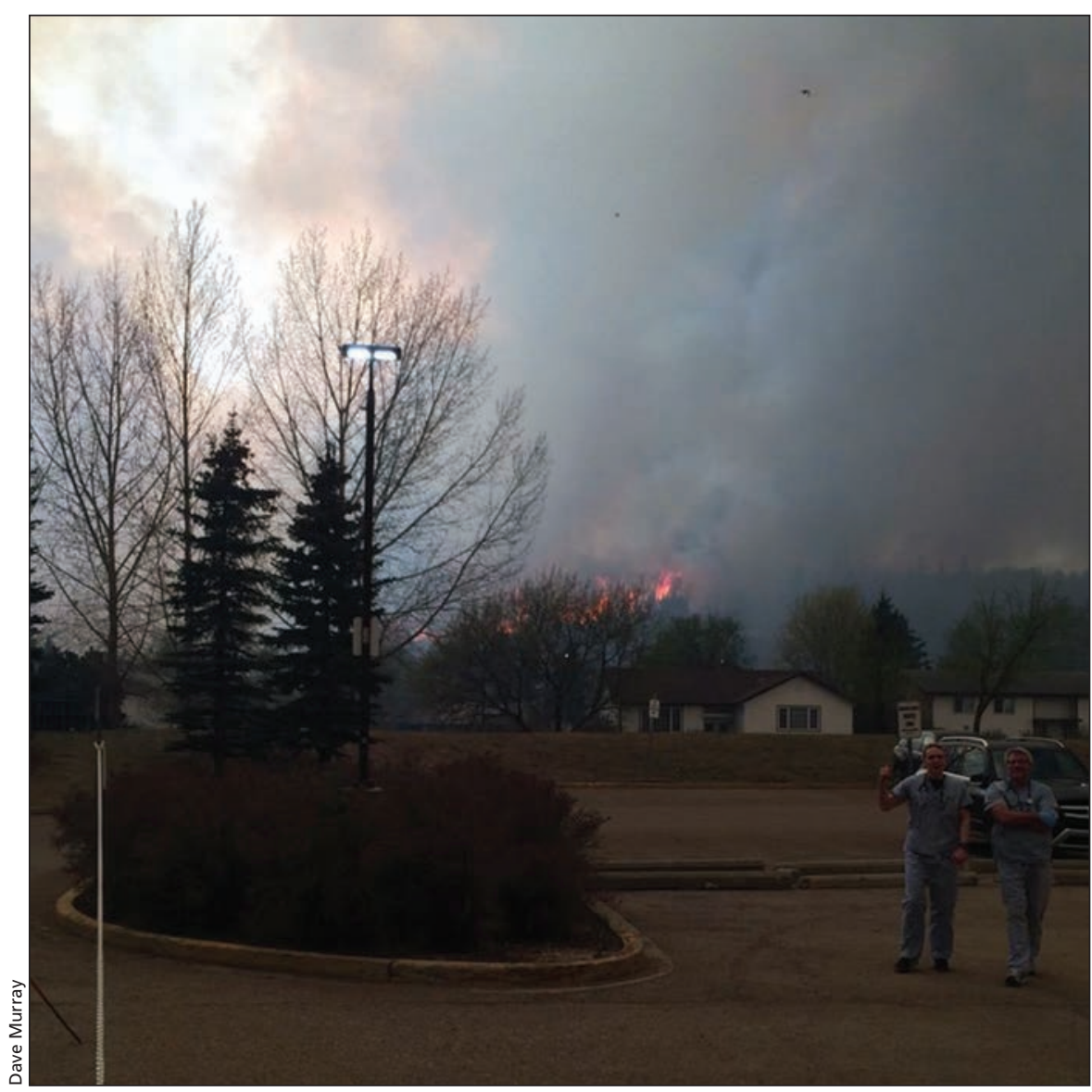

Doctors Paul Geoffrion (left) and John Bowman stepped out of Fort McMurray's emergency department to find the fire was closer than they'd thought.

shift, was sleeping in the doctors' residence when he was wakened by helicopters and water bombers flying on sorties to fight the fire. A neighbor told him the area was being evacuated.

Murray hurried to the hospital to see if he could help, only to find that no one had given staff an evacuation order. He urged Dr. Jonathan Bowman and Geoffrion to step outside the largely windowless ED. In the parking lot, ash was drifting onto the cars.

"We could see right across Highway 63 where the flames were jumping from treetop to treetop," says Bowman. "It was moving quickly. The smoke was pretty thick in the air. You could just hear this roar of fire. It was a surreal experience. You think: 'This can't be happening.' "'
Returning to the ED, Geoffrion met a firefighter/paramedic bringing in a patient. Over the firefighter's radio, he could hear orders to pull out of Beacon Hill - a neighbourhood just across the highway.

If the firefighters are abandoning a whole subdivision, "this thing's out of control," Geoffrion recalls thinking. That was the first time it hit him: "We really have to think about evacuation here."

Bowman, too, was gauging the distance between Beacon Hill and the hospital. A 22-year veteran of the hospital's ED, he was afraid they could soon be running for their lives.

"It was that close. If suddenly the wind just picked up ... it could be on us. Not in seconds, but in minutes. We 
needed to know what we were going to do if that happened," he says.

Inside the ED, there was still no word of an evacuation order, although it seemed administrators had called an emergency meeting for 3:30 pm. Much of Fort McMurray had already begun to empty. Some of the staff

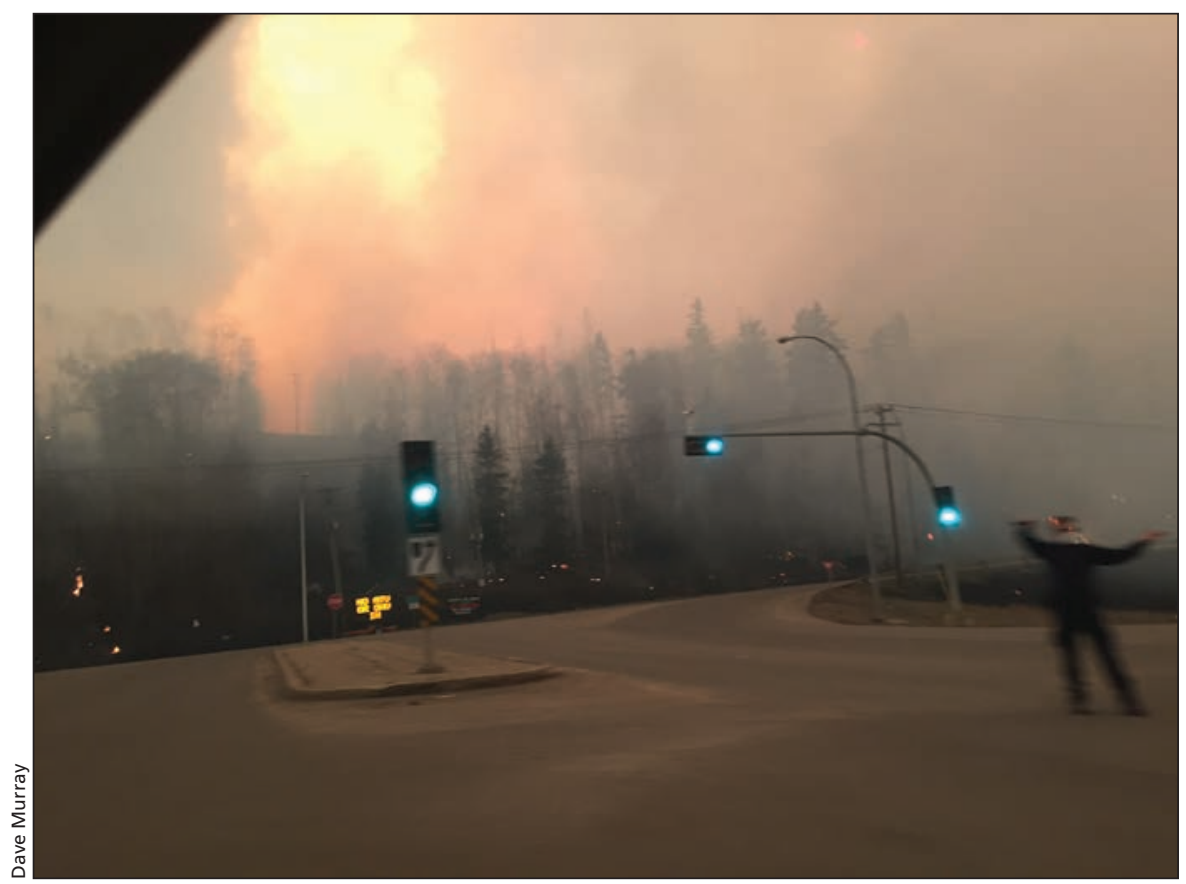

The view from a vehicle as staff took a few patients south to Anzac, where a local recreation centre had been set up to receive evacuees.

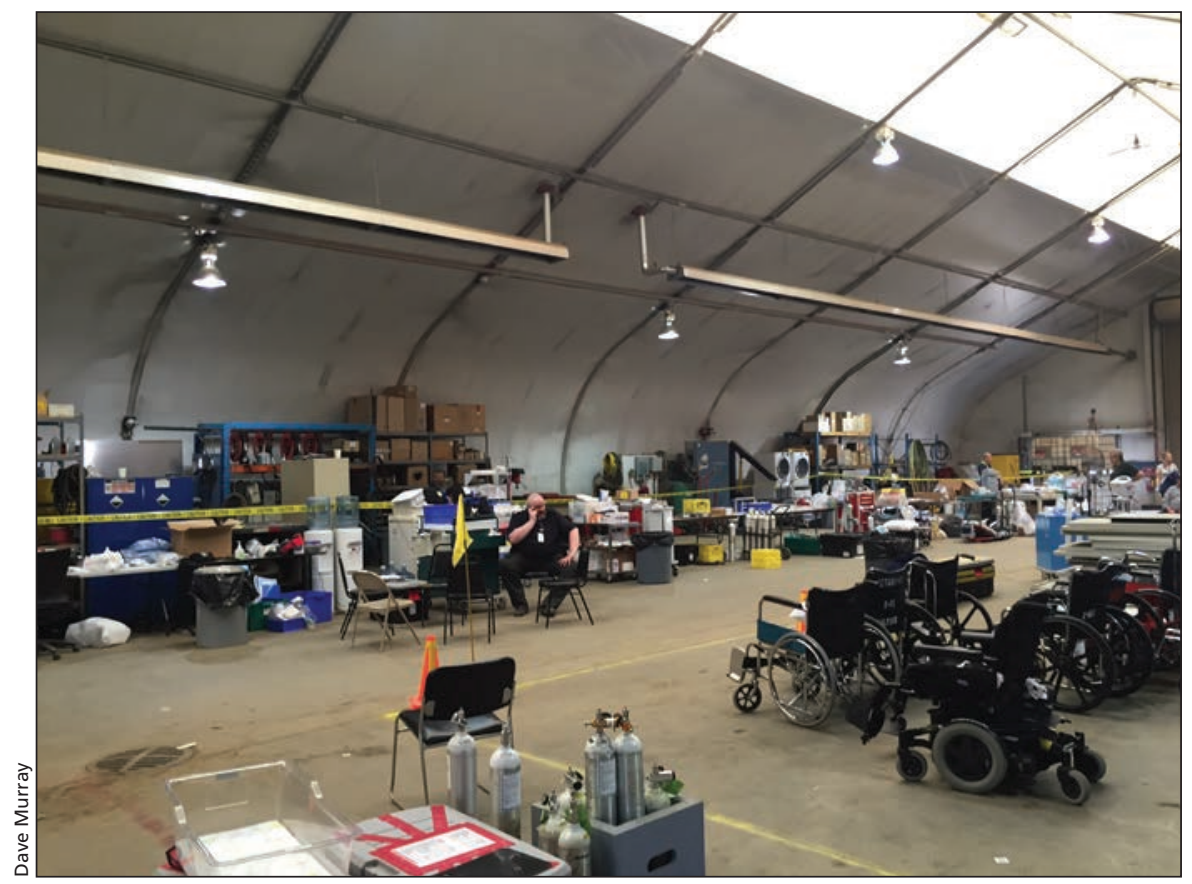

Staff await patients from the Ft. McMurray hospital after setting up a field hospital in a hangar at Firebag, a Suncor work site some 130 kilometres north of the city. order was likely coming. The nurses decided not to wait.

"We just started to load up bags, emptying in any medication we could find," Mellon says. The nurses threw gloves, tubing, bottles of saline, dressings, and suture kits into boxes near the front of the ED. They began moving patients out in wheelchairs and directing those who could walk to the waiting room.

At 3:30, hospital administrators told doctors, including Geoffrion and Murray, to sit tight. They were still waiting for word from the Emergency Operations Centre about whether to evacuate. The hospital had no direct access to the fire chief to learn about the fire's status or where it was headed. The ED doctors were told they'd get a call by four.

That deadline came and went. Patients, who had been following the fire's progress on their cell phones, began leaving. Geoffrion, Bowman and Murray were discharging others as fast as they could. By about 4:15, half the city was under an evacuation order.

Geoffrion looked at his watch: 4:46 and still no evacuation order, although another doctor arrived to tell them to get ready.

Without an official order, Lund and the doctors decided to act. They needed to get all the remaining patients out and ready to travel. Geoffrion summoned paramedics to load two intensive care unit patients into waiting ambulances.

Then Geoffrion, Murray, Mellon and Abby Boychuck, another nurse, turned their attentions to the patient with the dislocated shoulder; circumstances dictated "unorthodox" shoulder reduction. They needed the patient mobile enough to travel.

Buses were coming for all remaining patients in the hospital, Lund was told. But the core ED staff felt their sickest patients couldn't wait.

At 5:30, Geoffrion and Bowman piled into Mellon's SUV, along with a patient with chronic obstructive pulmonary disease on portable oxygen. Murray, a patient with a stabilized spinal fracture, the patient's mother and another passenger they picked up along the way piled into nurse Marill Bruce's pickup truck. 
The two vehicles joined thousands of others on Highway 63, driving through areas of blinding black smoke and columns of flame licking at the highway. With fires on both sides of the road, the doctors, nurses and patients passed exploding gas tanks at a service station. They saw a hotel engulfed in flames and a mobile-home park alight.

The Beacon Hill neighbourhood was completely gutted, "like a war zone," Bowman says. "Fires were everywhere."

Inside the SUV and the pickup truck, the patients were stable. Geoffrion kept trying to get news on his cellphone about where they should head. Bowman worried about whether people were being injured in the fire and would need help now unavailable at the empty hospital.

"It's a terrible feeling to think that we were being evacuated - and we were the hospital. Now where do people go that are being injured or are suffering from smoke inhalation?" he said.

The doctors and nurses tried to head north. But RCMP officers directed them south to Anzac, where a local recreation centre had been set up to receive evacuees. Then Mellon got a call from Lund. Seventeen patientfilled buses from the hospital were going north and they'd need ED doctors and nurses.

After unloading their patients in Anzac, the doctors and nurses made sure no one there had urgent health needs. Then they radioed for a ride north. Within an hour, three choppers arrived to pick up the health care workers and supplies. They headed to Firebag, a work site and airstrip for the Suncor energy company that had been designated as the emergency field hospital.

Bowman and Murray, both ex-military, were expecting a military field hospital when they landed. They were surprised to find a nearly empty hangar, with willing Suncor employees on hand who had sketched out three designated triage areas: red, yellow and green.

The supplies that the nurses had thrown into boxes and bags at the hos-

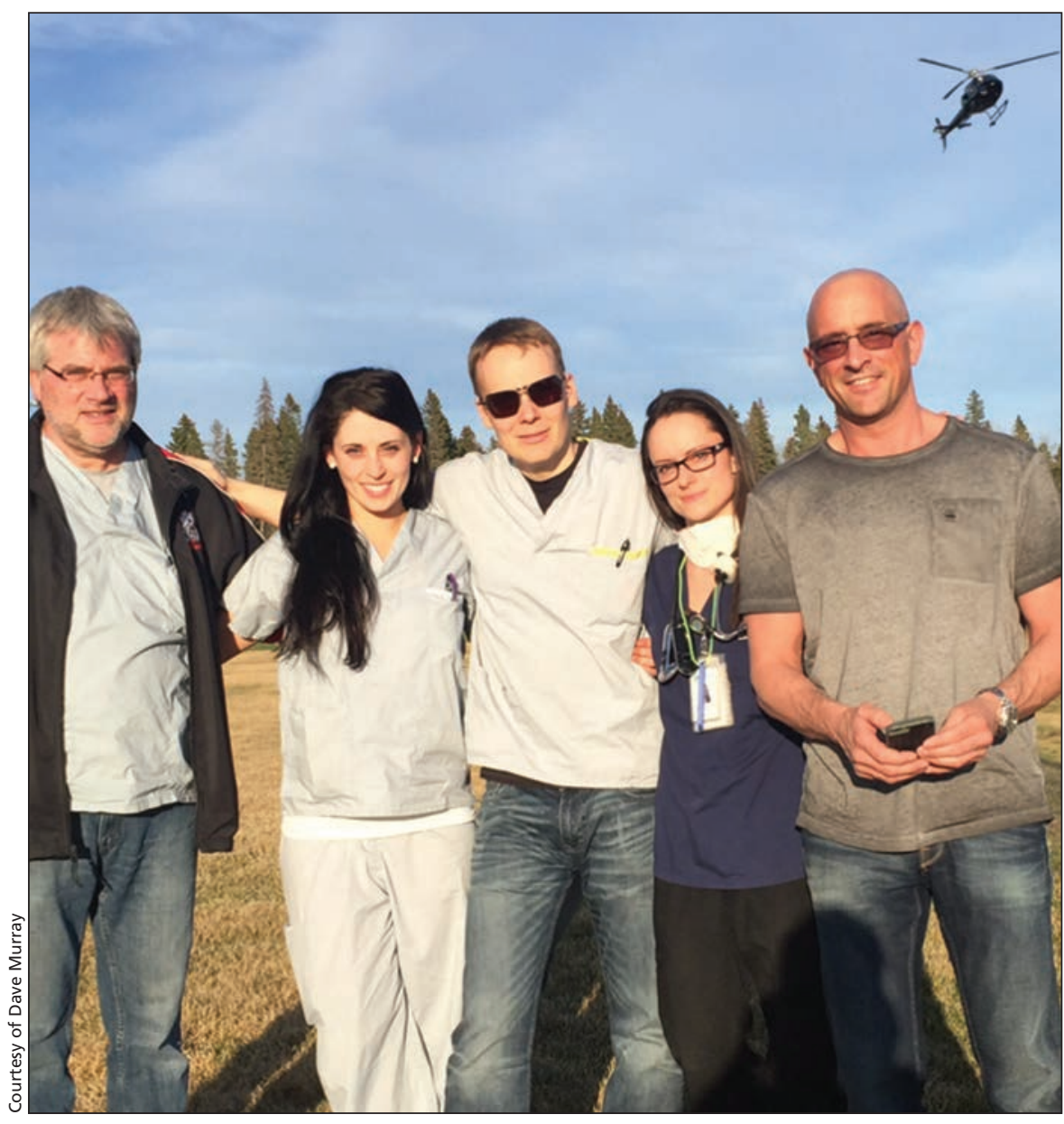

The experience forged a strong bond among emergency department staff, including (left to right) Dr. John Bowman, RN Julie-Ann Mellon, Dr. Paul Geoffrion, RN Marill Bruce and Dr. David Murray.

pital became the field hospital. Folding tables laid on the hangar floor and covered with blankets became makeshift beds. Suncor employees unbolted waiting room seats from the floor of the airport terminal to serve as chairs for ambulatory patients. As they organized what they could, the doctors waited.

It took the 17 buses and accompanying ambulances seven hours, instead of the normal two and a half, to make it through the streets clogged with cars to Firebag.

Confused and frightened long-term care patients, anxious patients with mental health issues, women who had just given birth and their babies, and tired, vomiting postsurgical patients spent the hours on the buses with few breaks, little food, and no bathrooms.

Between 12 and 1 am on Wednesday, May 4, the buses arrived at Firebag. Boarding the buses, the ED doc- tors and nurses directed accompanying friends and family members into the airport's waiting room. Then they triaged and tagged patients.

The hardest part was getting the patients off the buses and into the few wheelchairs and two stretchers. Doctors, nurses, and the hospital's senior operating director, David Matear, who had accompanied patients on the buses, went to work, physically lifting and carrying dozens of patients into the hangar. All told, there were about 120 patients on the buses.

WestJet planes and other fixedwing medevac aircraft were already on the tarmac. Patients were stabilized and boarded.

By $8 \mathrm{am}$, the team had cleared everyone. Amazingly, despite the turmoil, all the patients did well.

Believing their work was done, Bowman and Murray left on a flight with the last patients. Geoffrion went 
to grab a couple hours of sleep. He planned to catch a later flight.

When he woke up, he learned 25000 evacuees were headed toward the makeshift hospital. This time, Geoffrion was the only ED doctor on site, along with Matear and a handful of nurses, including Mellon. Once again, they worked through the day and night.
By the time their relief — including the ED chief - arrived on Thursday, Mellon was so glad to see them she cried.

As they recount the experience, the doctors and nurses are universal in their praise for one another. Working together throughout the fear, confusion and uncertainty over the fate of their city had forged a strong bond.
"I feel privileged to be part of this thing. When you face a crisis, that's when you can see people's true natures," says Geoffrion. "Those who stuck around - they were the real heroes. They put the team and everybody ahead of themselves." - Laura Eggertson, Ottawa, Ont.

CMAJ 2016. DOI:10.1503/cmaj.109-5280 